\title{
EMBAJADAS Y GUERRAS: \\ ALGUNOS PARADIGMAS COMPOSITIVOS EN EL AUTO SACRAMENTAL DE CALDERÓN ${ }^{1}$
}

\author{
Adrián J. Sáez \\ Westfälische Wilhelms-Universität Münster \\ Romanisches Seminar \\ Bispinghof $3 \mathrm{~A}$ \\ 48143 Münster. Alemania \\ saezgarc@uni-muenster.de / asaez@alumni.unav.es
}

[Anuario calderoniano (ISSN: 1888-8046), 5, 2012, pp. 215-231]

Entre los autos sacramentales de Calderón, un selecto grupo de cuatro obras historiales anclan su alegoría sobre los sucesos de la guerra de Cataluña, a saber: Lo que va del hombre a Dios (1642), El divino

${ }^{1}$ Este trabajo se ha beneficiado de mi participación como becario colaborador en el proyecto Red Europea: Autoridad y poder en el Siglo de Oro del Programa Jerónimo de Ayanz del Plan de Formación de I+D 2009-2010 del Gobierno de Navarra, cuyo investigador principal es Ignacio Arellano. Se complementa con «Doctrina, historia y política en cuatro autos de Calderón con la guerra de Cataluña al fondo", de próxima aparición, al que remito al interesado para mayores precisiones bibliográficas. 
cazador (1642), El socorro general (1644) y El lirio y el azucena (1660)2. Escritos durante el desarrollo del conflicto, ofrecen una visión cambiante de este tema de máxima actualidad, en estrecho contacto con la evolución de los acontecimientos que el dramaturgo conoce. En ellos, además, Calderón elabora un proyecto propagandístico y político destinado a deslegitimar la rebelión catalana y defender la causa española, dentro de su exaltación de la fe católica.

En estos autos de argumento bélico y circunstancial se aprecia una serie de estructuras recurrentes que pueden estudiarse como paradigmas compositivos, definidos por Arellano ${ }^{3}$ como "ciertas organizaciones sintácticas y semánticas, semejantes a los topoi de tradición grecolatina, definidas por un apreciable grado de formulismo y fijación estructural». Son estructuras que articulan el diseño de la arquitectura de los autos, parcial o globalmente, y que pueden funcionar en un nivel literal o según una doble lectura.

Los esquemas analizados se asientan en modelos profanos a partir del cual se sustenta la lectura «a dos luces», literal y alegórica, lo cual se explica al menos parcialmente por su composición en tiempos de guerra. Uno de los paradigmas que ya catalogaba Arellano era el alarde de ejército en el que un comisario reconoce las tropas, muy vinculado a los esquemas de corte militar que estudio a continuación ${ }^{4}$.

\section{LA EMBAJADA: VIS PACEM PARA BELLUM}

El primero de los arquetipos que se aprecia es la embajada, en general previa a los enfrentamientos. En una época convulsa, de hostilidades múltiples, la diplomacia desempeñaba un papel que no puede menospreciarse 5 . A título de ejemplo, Melo describe diversas embajadas entre ambos bandos en Guerra de Cataluña (1645): fray Bernar-

${ }^{2}$ Cito siempre por las ediciones consignadas en la bibliografia, de donde tomo las propuestas de datación.

${ }^{3}$ Arellano, 2001a, p. 20. También los ha aplicado a la poesía satírico burlesca de Quevedo: ver Arellano, 2003a, pp. 219-227. Algunas de los esquemas que comento pueden estudiarse en comedias de tema bélico, pero estas carecen de la doble faceta (política y religiosa) presente en los autos.

${ }^{4}$ Ver Galván, 2004b, pp. 31-35; 2006b, pp. 18-20, sobre ciertos paradigmas en La divina Filotea.

${ }^{5}$ Ver Reichert, 2007; Visceglia, 2008; Weller, 2009. 
dino de Manlleu presenta ante la Corte un memorial donde se denuncian los excesos de la tropa y se pide su salida de las provincias catalanas (II, 17); la petición de perdón real rechazada por los ministros de Felipe IV (II, 48); nuevas conversaciones entre los emisarios catalanes a espaldas de la Diputación (II, 52), etc. No debe extrañar, por tanto, el uso de este paradigma compositivo en autos sacramentales que dramatizan un enfrentamiento armado.

En El divino cazador, el nexo es seguramente menos claro que en otros autos: se representa el debate sobre la oportunidad del viaje del rey al frente de sus tropas, candente durante los primeros años del conflicto. Debido a la Culpa, los elementos no obedecen al Género Humano, virrey en la tierra por mandato del Príncipe. Entonces, el Género Humano intenta ir al alcázar real para informar de la situación, pero la Culpa lo derrota y se lo impide. Únicamente logra pasar el Albedrío, ya que esta facultad humana es superior al pecado original y a la concupiscencia. Al llegar junto al Príncipe, le dice:

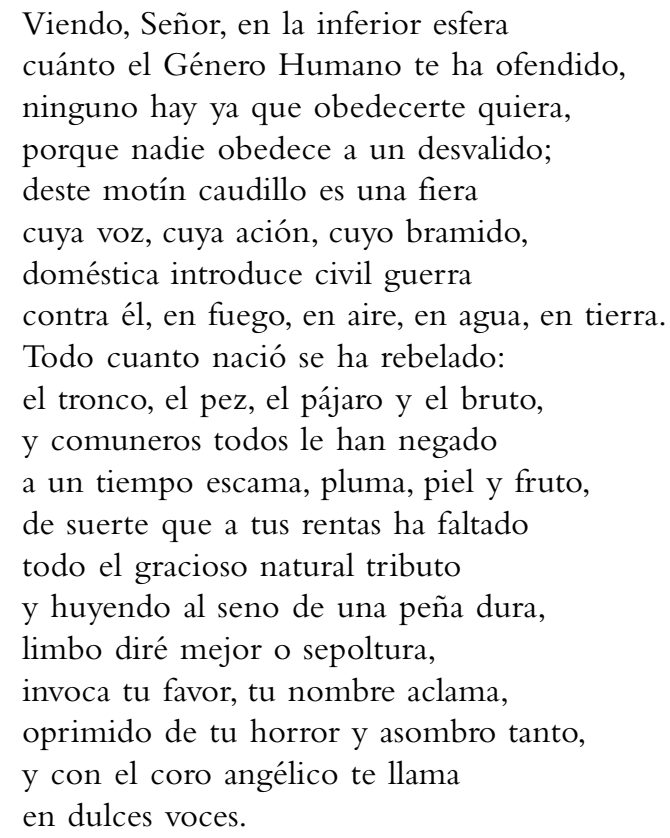

(vv. 640-659)

Aunque ya antes estaba apuntado, el sentido historial se aclara con la referencia a «civil guerra» (v. 646), término que usa Melo (Guerra 
de Cataluña, I, 7; II, 66). Greer ${ }^{6}$ afirma que la dramatización de esta embajada es «una mezcla muy astuta de doctrina católica y de psicología socio-política apropiada al contexto de 1642", porque presenta al Género Humano "como un gobernante cuya relación con su reino es paralela a la del odiado Conde-Duque, y a la vez como un virrey asediado, humillado e impotente", mientras su imagen de «labrador anciano, vulnerable y angustiado» podría funcionar "para disminuir la hostilidad del pueblo rebelde madrileño hacia el poderoso privado». Sin embargo, en el contexto historial de la revuelta catalana parece más verosímil pensar que se dramatiza la petición de ayuda del virrey de Cataluña ante el acoso de los rebeldes que le causarán la muerte. Así, a mi juicio, se entiende mejor la súplica del Género Humano ante la partida del Príncipe, que le deja solo ante el peligro. El parlamento surte efecto y el Príncipe desciende y acaba dando caza a la Culpa, escondido tras «un árbol con una cruz» (acotación v. 1181).

Dos embajadas se dramatizan en El socorro general. Ante las reformas propuestas por el virrey, la Sinagoga se rebela y le da «violenta muerte» (v. 71), claro eco del Corpus de Sangre. La reacción del "católico monarca» (v. 145) no es la venganza, aunque lo crea la Apostasía, sino el envío de «doce valientes ministros» (v. 152), con los que

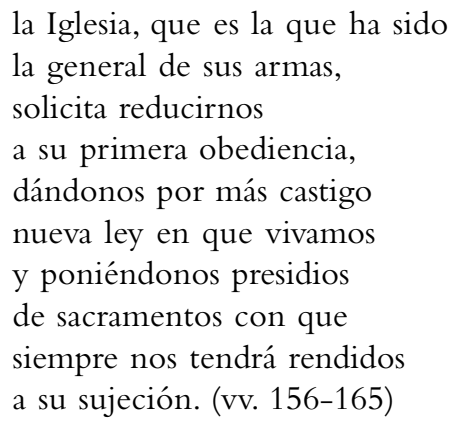

Claramente, los ministros son los apóstoles y los emisarios reales. No obstante, la Sinagoga se mantiene en su decisión de no abandonar su libertad y sus leyes, los fueros catalanes y la Ley Escrita de los judíos. Teniendo ya a las puertas de Jerusalén «su grande ejército altivo» (v.

${ }^{6}$ Greer, 1997, p. 227. 
166) no se rinde, se declara «Libre república» (v. 175) y anima a combatir contra la ley de Cristo.

La llegada del Bautismo, emisario "vestido de blanco a la española» (acotación v. 205), identifica a la España de los Austrias con la religión católica. Acude enviado por la Iglesia para tratar de solucionar el conflicto sin tener que llegar al enfrentamiento y defiende que no se pretende romper ningún fuero, pero la embajada fracasa: negativa judía y fracaso de los emisarios reales en sus conversaciones con los diputats. No es preciso identificar esta embajada con ninguna real y precisa, pero refleja esta opción política manejada por la monarquía hispánica, como la visita de don Antonio Francés ${ }^{7}$. Primeramente se ha ofrecido la conciliación pacífica, rechazada por los amotinados, que no aceptan la nueva ley pese a que es solo un modelo más perfecto de la anterior. Volveré luego sobre la acción de este auto, pero ahora me interesa analizar la pertinencia del estatuto de heraldo del Bautismo.

Este sacramento es el emisario porque se trata del primero que se administra en la vida del hombre y la puerta de acceso al seno de la Iglesia y a la vida de la gracia, al igual que su intercesión ofrece reintegrarse a España. Asimismo, el Bautista es el último de los profetas, la voz que finalmente anuncia la venida de Cristo (basado en Malaquías, 3, 1; Isaías, 40, 3-5; Lucas, 3, 4; Juan, 1, 23): en este sentido, suele aplicársele la metáfora del lucero del día que anuncia la salida del sol, símbolo de la realeza humana y divina. Según estudia Galván ${ }^{8}$, además, Calderón enmarca a este personaje dentro de «una tradición exegética que señala a san Juan Bautista como ministro o valido del Rey Cristo, y por tanto como modelo para todos los que desempeñan esos cargos». En Política de Dios (1626, primera parte), Quevedo presenta a Cristo como modelo del rey y ofrece un ejemplo para el perfecto ministro9: «Era san Juan Bautista grande privado de Dios y el que venció todas las malas andanzas del puesto. No ha habido, ni habrá mal paso en la privanza, que él no padeciese y le santificase con su humildad, y con su vida y con su muerte» (II, 19, p. 250). Sus obras y palabras constituyen la guía de digno comportamiento para los pri-

\footnotetext{
${ }^{7}$ Arellano, 2001b, p. 20.

${ }^{8}$ Galván, 2004a, p. 81.

${ }^{9}$ Cito por la edición de Crosby, 1966. Sigo criterios GRISO.
} 
vados, una suerte de «espejo de ministros» que les ha de enseñar a ser humildes y justos, los límites de su cargo, etc., etc. También este personaje es embajador del rey-Dios en Llamados y escogidos, donde invita a las bodas divinas, y en El maestrazgo del Toisón, investido también como gran canciller de tal orden.

Más desarrollado y con mayor relevancia dramática aparece el paradigma en El lirio y el azucena, donde es principio y fin del conflicto. Mediante tretas, la Discordia quiere enfrentar a Francia y España para evitar la unión de las dos monarquías católicas, y la rebelión catalana que encarna el personaje es la excusa elegida. Antes de que comience la guerra, acude el Brazo Seglar ataviado con «cruz verde de Alcántara y llave dorada", el símbolo de la Inquisición y uno de los atributos de san Pedro. Es el Bautismo (v. 545), que en el nivel historial representa a don Luis de Haro, canciller mayor y registrador del Consejo de Indias, con una importante función en las negociaciones que culminaron en la Paz de los Pirineos. Enviado de Felipe IV, rey de la Gracia, reclama que la Sinagoga reconozca su «natural vasallaje» (v. 527) y admita a un virrey que le gobierne. Pero la Sinagoga lo rechaza y se constituye en «república libre» (v. 567). El significado historial es cristalino: sublevación de Cataluña, asesinato del virrey y rechazo de la embajada que ofrece concordia. Una vez más se enfatiza la oferta de paz como primera opción, siendo las armas solo el resultado de la pertinacia del atrevimiento rebelde (vv. 567-578).

Declarada la guerra con el Brazo Seglar, la Discordia pide ayuda a la Ley Natural, Francia. Responde a su llamada el Brazo Eclesiástico, que representa al cardenal Mazarino, ministro de Luis XIV, quien se ofrece a luchar contra su enemigo católico aunque parezca carecer de motivo alguno:

\author{
Cuando no fuera el pretexto \\ tan natural, por ver solo \\ el canto del gallo opuesto \\ al rugido del león, \\ de parte el favor te ofrezco \\ de mi gran ley. (vv. 622-627)
}

Frente al diabólico gallo, asociado con el basilisco y la serpiente (Quevedo, La rebelión de Barcelona ni es por el güevo ni es por el fuero, 
hacia 1641$)^{10}$ y símbolo de la casa real francesa, se enfrenta el león, emblema divino (junto al cordero) que adorna el escudo de España ${ }^{11}$. Después, la Paz se entrevista con ambos reyes para tratar de interceder en el conflicto, pero aunque los dos desean el cese de los combates, ninguno da el primer paso. Únicamente cuando un clamor inspirado por la Paz domina sus campamentos, aceptan sellar el fin de la guerra, ratificado con el matrimonio ente sus hijos, María Teresa y Luis XIV, según se establece en la Paz de los Pirineos de $1659^{12}$.

La embajada como propagación de la fe (Diego en España en El maestrazgo del Toisón), o los chistes sobre la inutilidad de las misiones diplomáticas de los turcos (El cubo de la Almudena, vv. 367-368...), más su presencia y función en las comedias, son variantes del paradigma en las que no puedo detenerme.

En resumen, la embajada es un componente más de las relaciones políticas en el Siglo de Oro que en los autos remite a la búsqueda de la armonía universal y a las pretensiones de paz de España, paladín de la defensa cristiana, frente a la tenacidad bélica de sus enemigos. Es una estrategia que ya Julio César había empleado: dentro del programa político y legitimador que desarrolla en sus Comentarios a la guerra civil (I, 26; I, 85; III, 90...), insiste en su persistente búsqueda de la paz frente a la preferencia bélica de sus rivales pompeyanos. Leído en el contexto del siglo, cabe recordar la imagen de España como defensora de la paz y de la Cristiandad que Olivares quería presentar ante Europa en 1634, en vísperas del estallido de la guerra con Francia, un argumento repetido en la diplomacia española ${ }^{13}$.

Asimismo, si el género autosacramental en conjunto suele considerarse investido con un marcado belicismo, el final de El lirio y el azucena debe servir, según ya viera Galván ${ }^{14}$, para matizar esta afirmación.

${ }^{10}$ Arredondo, 2011, p. 101.

11 Recuérdese el significado opuesto o complementario de ambos animales, las dos caras de Dios y del monarca: firmeza y castigo (león) frente a misericordia y perdón (cordero). Mexía recoge en la Silva de varia lección, II, 2, pp. 300-306, la creencia del miedo del león hacia el gallo, no operativa en el auto, por supuesto.

12 Ver Usunáriz, 2006, pp. 332-401, con la transcripción del documento.

13 Arredondo, 2011, pp. 39 y 69. Pero a la vez, la defensa de la paz consideraba el uso de las armas, como prueba el caso de Saavedra Fajardo (p. 86), y con los años lograr la paz era necesario para una nación acosada.

${ }^{14}$ Galván, 2004a, p. 72. 
En este auto, antes de la solución irénica no se representa ninguna batalla y la carga argumental reposa sobre las gestiones diplomáticas entre los distintos bandos. Y a pesar de que la guerra haya sido declarada entre Francia (Ley Natural) y España (Ley de Gracia) debido a los tejemanejes de Discordia (Cataluña), se enfatiza la necesaria y lógica alianza entre las dos mayores naciones católicas.

Paradigmas bélicos: el asedio, la Alianza, LA GUARda y El SOCORRO

Amén de estas estructuras a caballo entre la paz y la guerra, se hallan otras más arraigadas en las batallas. En El socorro general se dramatizan diferentes estrategias de ataque y defensa dentro de un conflicto presentado con bastante detalle y desarrollo, tal vez configurado a raíz de los recuerdos de Calderón acerca del sitio de Tarragona, en cuyo socorro participó junto con su hermano en 1641. Este auto será el hilo que enlace con otros textos que presentan los mismos motivos.

Una vez comienza la batalla, la Sinagoga no puede contener la embestida de la Iglesia y sus miembros, del mismo modo que el bando catalán se ve en principio superado por las acometidas españolas. La Sinagoga huye y busca el auxilio de la Gentilidad, los franceses: reflejo de la petición de ayuda de Cataluña a Francia para luchar contra España, ratificada el 23 de enero de 1641 con la jura de obediencia a Luis XIII a cambio de recibir protección militar. Recuérdese que ya durante las guerras entre la Generalitat y Juan II, entre 1462 y 1472, los rebeldes ofrecieron el trono a René de Anjou, conde de Provenza y tío de Luis XI, entre otros candidatos.

Sin embargo, el remedio es peor que la enfermedad: las tropas auxiliares enviadas pronto señorean tierras catalanas y quienes buscaban libertad van a ser dominados por un poder más centralista (ver vv. 700-702), cuyo equivalente en el sentido religioso es la esclavitud del pueblo judío frente a Roma. Franceses y catalanes, gentiles y judíos, unen sus fuerzas para luchar contra los españoles, quienes sufren además el acoso de las flotas protestantes (vv. 871-876) y se ven cercados por todos los frentes (v. 794).

Pero la Iglesia no puede ser vencida aunque sufra derrotas y contratiempos. Envía a la Oración en busca de pan y vino, «auxilios / suficientes y eficaces» (vv. 919-920). Mientras esperan estos «socorros generales» (v. 922), las tropas españolas se fortifican con «diez fuertes 
baluartes» (v. 964): los mandamientos que guardan a la Iglesia de los ataques del diablo, simbolizados por los catalanes.

Es el paradigma de la plaza sitiada, motivo ya presente en la tradición clásica (Ilíada), que en la literatura bíblica y religiosa se convierte en el tópico de la ecclesia militans en actitud defensiva, muy relacionado con la destrucción y posterior triunfo de Jerusalén. También aparece en la literatura alegórica profana (Roman de la Rose) y otros textos medievales ${ }^{15}$. Santa Teresa, gustosa lectora de libros de caballerías, dio nueva vida al motivo en su Castillo interior (1577) mediante la equiparación de las fases espirituales hacia la interiorización y el acercamiento a Dios con los elementos estético-espaciales de la fortaleza rodeada de enemigos que deben superarse para entrar y que debe guardarse de la gran guerra que da el demonio ${ }^{16}$. Es imagen alegórica frecuente que Calderón emplea también en La iglesia sitiada y El cubo de la Almudena, piezas donde el argumento es el sitio de un castillo o una ciudad (Tirlemont y Madrid) que, a la par, simboliza la Iglesia católica.

Es un emblema idóneo para representar conflictos en los que religión y política iban de la mano: la guerra, así, sustenta una lección profana (política) y espiritual (católica) al mismo tiempo. Muy claro es en El socorro general: la Iglesia dispone las funciones de todos los sacramentos dentro de las fortificaciones, en una perfecta trabazón entre historia y alegoría. Según Arellano, «En la distribución de las tareas se ofrece una lección de doctrina sacramental» ${ }^{17}$ : así, el Bautismo debe guardar la puerta principal, la Comunión ha de asistir a los enfermos, etc. En La divina Filotea se combate por el alma en gracia que en el baluarte espera la llegada de su divino esposo, quien la salva de las pretensiones del Demonio. Se halla protegida por el cuerpo humano, que el Demonio expone en «metáfora de castillo» (v. 155): ambos están hechos de tierra, tienen órganos de gobierno (el cerebro es el Consejo de Estado, el corazón el Consejo de la Guerra), los sentidos y las virtudes son vigías y soldados, etc. En ambos casos recuerda la arquitectura simbólica del Castillo interior, donde la cerca es el cuer-

15 Galván, 2006a, pp. 216-217; 2006b, pp. 12-13, 15-17. Para las fuentes ver también Arellano, 2001b, pp. 28-30; Poppenberg, 2000, pp. 91-98, cita el anónimo auto El castillo de la $\mathrm{Fe}$, de fines del siglo XvI.

16 Sobre el origen y la génesis de la imagen ver la síntesis crítica de Chicharro, 1999, pp. 93-121.

17 Arellano, 2001b, p. 29. Muy similar en El cubo de la Almudena, vv. 503-615. 
po, la puerta a las moradas es la oración y las potencias del alma son guardas y alcaides.

El empleo de este modelo se asienta en el lugar de representación: Toledo, que merced a su etimología (Toledo o Toletot, "junta de muchos, unión de naciones, o de gentes') se erige en arquetipo de fidelidad a la corona y a la Iglesia, "plaza de armas de la fe» (v. 466) ${ }^{18}$. Pero no solo.

Durante los siglos XVI y XVII, el panorama bélico cambió con la construcción de mejores plazas fuertes y baluartes. La introducción de las armas de fuego y la adopción de bastiones en ángulo y otras fortificaciones defensivas de trace italienne (revellines, coronas, hornabaques) originaron, con el tiempo, guerras de mayor duración y estrategias más complejas ${ }^{19}$. El asedio a una fortaleza precisaba de un gran ejército con un buen sistema de abastecimiento para extensos períodos. Por otro lado, comprendía el levantamiento de un conjunto de obras ofensivas y defensivas (una doble línea fortificada), bombardeos de baterías y morteros, intentos de zapar y minar las murallas para su derribo, tentativas de asalto y defensa de las escaramuzas rivales... A su vez, los defensores habían de soportar las privaciones derivadas de su aislamiento, frenar las acometidas y tratar de romper el cerco, en espera del apoyo militar que les auxiliase. Tales maniobras estaban a la orden del día en las guerras europeas, sin que falten ejemplos en territorios hispánicos: San Quintín (1557), Nördlingen (1634), Las Dunas y Badajoz (1658), etc. ${ }^{20}$ El caso de Fuenterrabía fue, sin duda, uno de los más notables del momento: sufrió asedio entre julio y septiembre de 1638 por las tropas francesas bajo el mando del príncipe de Condé (posterior aliado español). Aunque liberada finalmente, al inicio la noticia causó asombro y espanto, dio lugar a di-

18 Ver Arellano, 2003b, para mayores detalles. Es una etimología presente en todos los autos escritos para Toledo: Psiquis y Cupido (luego reescrito para Madrid), Llamados y escogidos, etc. También se documenta en comedias como Origen, pérdida y restauración de la Virgen del Sagrario (pp. 488-489).

${ }^{19}$ Ver Parker, 1990, pp. 23-117; 2010, pp. 69-119, 173-193. Algunas de estas construcciones son referidas en los autos: El cubo de la Almudena, vv. 944, 1309; La divina Filotea, v. 388...

${ }^{20}$ Ver Sáez Abad, 2010. 
versas relaciones ${ }^{21}$, y es hecho aludido en diferentes pasajes de la comedia No hay cosa como callar de Calderón.

A la par, el programa iconográfico del Salón de Reinos del Palacio del Buen Retiro incluía, entre los doce lienzos de batallas, varias pinturas de célebres asedios y refuerzos para las armas hispánicas: El socorro de Génova de Antonio de Pereda, La rendición de Jülich y El socorro de Breisach de Jusepe Leonardo, El socorro de Constanza y El sitio de Rheinfelden de Vicente Carducho, La recuperación de Bahía de Juan Bautista Maino, y La rendición de Breda o Las lanzas de Diego de Velázquez ${ }^{22}$. Precisamente al sitio de esta ciudad brabantina dedicó Calderón la comedia El sitio de Bredá. Coenen ${ }^{23}$, en su análisis de esta comedia y de Amar después de la muerte, concluye que las ideas de Calderón sobre el arte de sitiar y la guerra en general muestran una preferencia por las tácticas militares que reducen la violencia, el trato respetuoso a los vencidos y la falta de rigor excesivo. Todo ello configura un horizonte de expectativas que complementa la imagen alegórica modelada desde la Antigüedad, sin olvidar la frecuencia de los cercos en las obras de temática histórica de Lope de Vega.

De nuevo en El socorro general, el hambre y las penurias se ciernen sobre los sitiados, a la espera del auxilio divino. La Apostasía desiste en esta situación y huye con la Gentilidad y la Sinagoga (vv. 12511253). Esta alianza maligna ya aparece en otros autos de Calderón, y en general mantienen la cifra de miembros y la fuga de uno de los asediados, débil en la fe: en La iglesia sitiada se juntan Gentilidad, la Secta de Mahoma y Judaísmo (vv. 1-170), a quienes se une la Herejía, traidor y rebelde del bando cristiano que se identifica con Lucifer y acaba solo en su lucha; Alí y la Idolatría se suman al plan bélico de la Secta de Mahoma en El cubo de la Almudena, y luego se les une la Apostasía; en El arca de Dios cautiva se juntan Idolatría y Goliat con-

21 Por ejemplo, el Sitio y socorro de Fuenterrabía (1629), de Juan de Palafox y Mendoza, o el Sitio de Fuenterrabía (1655, original latino romanceado en el siglo XVIII), de José de Moret.

22 También en la misión de retomar el control de la isla de San Martín hubo un asedio de ocho días en junio de 1633, pero su representación pictórica (La recuperación de Puerto Rico, de Antonio Cajés) no se centra en ello. Ver Brown y Elliott, 1988.

${ }^{23}$ Coenen, 2008. Ver también Güntert, 2011, pp. 59-77, 157-178. Otros asedios en Amar después de la muerte, Judas Macabeo, La puente de Mantible, también en El segundo Escipión... 
tra el pueblo hebreo; Noche se alía con Idolatría, Hebraísmo y Apostasía en El día mayor de los días, etc. Al comienzo de La divina Filotea, el Demonio convoca al Mundo y a la Lascivia «[...] en fe / de la inviolable jurada / alianza de los tres» (vv. 22-24) para que, como enemigos del alma, le ayuden a sitiar al cuerpo humano. Para la lucha, el Mundo recluta a Ateísmo, Gentilidad, Hebraísmo y Apostasía.

Para Poppenberg ${ }^{24}$, la unión presente en El socorro se identifica con los neerlandeses, ingleses y franceses, aliados desde la década de 1620 en la guerra de Flandes, de modo que «el auto sacramental se integra en la política guerrera de Olivares y la carga de energía apocalíptica». Sin embargo, este paralelismo no es unívoco y constante, pues los enemigos en el ámbito religioso no siempre se equiparan a los mismos rivales político-militares. Por ello, este conjunto (entre dos y cuatro miembros) constituye un frente común que se enfrenta a la religión cristiana y que, en todo caso, puede conformar una imagen inversa a la Santa Liga compuesta por España, Venecia y el Papado, memorable coalición cristiana que derrotó a los turcos en Lepanto (1571) y que El Greco ya había explorado simbólicamente en su Alegoría de la Santa Liga (1577-1580). Los tratadistas, asimismo, insistían en la necesaria unión entre naciones católicas (especialmente España y Francia) contra los herejes e infieles y criticaban la primacía de la razón de Estado ${ }^{25}$.

Igualmente, la deserción de soldados era frecuente en los ejércitos modernos y en los asedios podía afectar a ambos bandos, víctimas de las guerras de desgaste ${ }^{26}$. Leído desde las letras divinas, este fenómeno se identifica con la Reforma protestante, nuevos enemigos políticoreligiosos surgidos en el seno de dominios cristianos.

Para prevenirse de ataques los cercados organizan una centinela formada por el Bautismo, la Penitencia y el Sacerdocio, que tienen por consigna «un Dios humanado y sacramentado». Según Suárez de Figueroa, «las debidas guardas son la vida de las ciudades, de los ejércitos, de las fortalezas, de los puertos y playas» (Plaza universal de todas

${ }^{24}$ Poppenberg, 2000, p. 92.

${ }^{25}$ Recuérdese solo la empresa 93 de Saavedra Fajardo («Impia faedera»), que representa dos montes unidos, uno de los cuales es el Vesubio en erupción: avisa del peligro de aliarse con infieles, porque los odios de base religiosa acaban por salir a la superficie con gran violencia. Ver Strosetzki, 2010, a propósito de la paz y la legitimación de la guerra.

26 Ver Parker, 1990, pp. 86-89. 
ciencias $y$ artes, II, 88, p. 885), materia en la que «merecieron los españoles la palma de vigilantes y osados», siendo inventores de las "centinelas perdidas» $(\text { p. 887 })^{27}$. Nuevamente se ve la imbricación de las letras humanas con el sentido teológico, porque la vigilancia de una ciudad se convierte en defensa de la doctrina católica contra la que fallan los enemigos (Sinagoga, Apostasía y Gentilidad) al negar cada uno de ellos un elemento doctrinal según su deficiente conocimiento de la fe. Repetido en otros autos (El día mayor de los días, La iglesia sitiada), es un patrón que Entwistle ${ }^{28}$ denomina «metáfora de los tres pasos (tres grados, o gradas, de acercamiento a la verdad revelada)", aunque en realidad puede constar de tantas fases como enemigos (cuatro en El cubo de la Almudena). Con mayor detalle y desarrollo dramático se presenta en La divina Filotea: la centinela armada de la Fe, la Esperanza y la Caridad tienen por nombre, seña y contraseña, «Dios uno y trino, verbo encarnado y sacramentado en pan y vino" (vv. 929-934). Aquí el paradigma es doble: frente a la posta del Bautista y la Oración, la Lisonja custodia el campo de la Sinagoga.

El asalto se salda a favor de la Iglesia y los enemigos cambian de táctica: esperan su rendición por la falta de alimento. Uno de los objetivos primordiales del cerco era impedir el abastecimiento (ver César, Comentarios..., III, 47), que alegóricamente bien puede simbolizar la Eucaristía, sustento esencial de la vida cristiana (La iglesia sitiada, vv. 204-216; El cubo de la Almudena, vv. 254-270, 1485-1487, 1670-1682; La divina Filotea, vv. 460-466...). Aunque esperan recibir auxilio, creen que será difícil pues les rodean «dos ejércitos por tierra / y una armada por la mar» (vv. 1432-1433).

Pero al final acude la nave del mercader (conocido símbolo de la Iglesia), que capitaneada por san Pedro e impulsada por los vientos del Austro vence a la flota de la Apostasía ${ }^{29}$. Así, las tropas españolas lo-

27 Suárez de Figuerosa traduce La piazza universale di tutte le professioni del mondo, de Tomaso Garzoni, pero con cortes, correcciones e interpolaciones añadidas, como la segunda cita en la que ensalza a los españoles.

${ }^{28}$ Entwistle, 1948, p. 226. Ver Regalado, 1995, p. 35. Galván, 2006b, p. 34, afirma que no es un paradigma stricto sensu. En Llamados y escogidos, la Verdad proclama un Dios con las características citadas en sus invitaciones a los desposorios del Príncipe (Cristo) y la Esposa (Iglesia), pero la Gentilidad y la Sinagoga no le creen, pues uno es politeísta y la otra niega su venida.

${ }^{29}$ Ver Suárez Miramón, 2011. 
gran paliar su hambre (humana y espiritual) gracias al pan eucarístico, proporcionado por la Virgen María en El cubo de la Almudena. Se repite en La divina Filotea: mientras los sentidos se alimentan, la Apostasía se apoya en el testimonio de la Vista, el Olfato y el Gusto para negar que sea "carne y sangre [...] para el socorro del alma» (vv. 1665-1666), dogma de la transubstanciación que acreditan el Oído y la Fe. Naturalmente, esta ayuda particular remite a la salvación final en Dios.

Todos estos esquemas bélicos o combativos, claramente son ramificaciones de la Iglesia militante, que representan la constante defensa de la fe cristiana, que no se rinde ni ante la peor adversidad, según la pintura trazada por el dramaturgo. El socorro es la salvación frente al asedio, la ayuda que cambia las tornas en la batalla, y, si se quiere, la puerta a la gloria eterna tras los padecimientos en vida, el merecido premio tras la lucha y el sacrificio.

\section{FINAL}

Anclados en la realidad del momento y en modelos profanos, estos paradigmas cobran nuevo significado al pasar por el tamiz alegórico: la embajada sirve a fines propagandísticos porque legitima la actuación de las armas hispánicas como ulterior recurso para mantener la Pax austriaca, mientras los diversos patrones bélicos (asedio, alianza, centinela y socorro) recrean tácticas militares habituales para remitir, en última instancia, al designio salvífico divino, al permanente auxilio de la Iglesia y a la constante defensa española de la religión. Este pequeño repaso a algunos esquemas estructurales confirma, en fin, la riqueza de elementos micro y macrotextuales con que Calderón teje el complejo y variado entramado alegórico de sus autos sacramentales. 


\section{BiBLIOGRAFÍA}

Arellano, I., Estructuras dramáticas y alegóricas en los autos de Calderón, Kassel, Reichenberger, 2001a.

- (ed.), P. Calderón de la Barca, El socorro general, Pamplona / Kassel, Universidad de Navarra / Reichenberger, 2001b.

- Poesía satírico burlesca de Quevedo, Madrid / Frankfurt, Iberoamericana / Vervuert, 2003a. [Reedición de su tesis doctoral: Pamplona, Eunsa, 1984.]

— «Toledo, plaza de armas de la fe, y los autos toledanos de Calderón», en "Estaba el jardín en flor...» Homenaje a Stefano Arata, Criticón, 87-88-89, 2003b, pp. 59-75.

Arredondo, M. ${ }^{a}$ S., Literatura y propaganda en tiempo de Quevedo: guerras y plumas contra Francia, Cataluña y Portugal, Madrid / Frankfurt, Iberoamericana / Vervuert, 2011.

Brown, J., y Elliott, J. H., «Rey y valido en el Salón de Reinos», en Un palacio para el rey. El Buen Retiro y la corte de Felipe IV, Madrid, Alianza / Revista de Occidente, 1988, pp. 149-202.

Calderón de la Barca, P., El arca de Dios cautiva, ed. C. Buezo, Pamplona / Kassel, Universidad de Navarra / Reichenberger, 2001.

- El cubo de la Almudena, ed. L. Galván, Pamplona / Kassel, Universidad de Navarra / Reichenberger, 2004.

- El día mayor de los días, ed. I. Arellano y M. Zugasti, Pamplona / Kassel, Universidad de Navarra / Reichenberger, 2004.

- La divina Filotea, ed. L. Galván, Pamplona / Kassel, Universidad de Navarra / Reichenberger, 2006.

- El divino cazador, ed. H. Flasche y M. Sánchez Mariana, Madrid, Dirección General de Bellas Artes, Archivos y Bibliotecas, 1981.

- La iglesia sitiada, ed. B. Baczyńska, Pamplona / Kassel, Universidad de Navarra / Reichenberger, 2009.

- El lirio y el azucena, ed. V. Roncero, Pamplona / Kassel, Universidad de Navarra / Reichenberger, 2007.

- Llamados y escogidos, ed. I. Arellano y L. Galván, Pamplona / Kassel, Universidad de Navarra / Reichenberger, 2002.

- El maestrazgo del toisón, en Obras completas III. Autos sacramentales, ed. Á. Valbuena Prat, Madrid, Aguilar, 1952, pp. 889-913.

- Origen, pérdida y restauración de la Virgen del Sagrario, ed. S. Fernández Mosquera, en Segunda parte de comedias, Madrid, Fundación José Antonio de Castro, 2007, pp. 479-557.

- Lo que va del hombre a Dios, ed. M. ${ }^{a}$ L. Lobato, Pamplona / Kassel, Universidad de Navarra / Reichenberger, 2005.

- El socorro general, ed. I. Arellano, Pamplona / Kassel, Universidad de Navarra / Reichenberger, 2001. 
CÉsAr, J., Guerra de las Galias. Guerra civil, ed. y trad.V. García Yebra, H. Escobar Sobrino, J. Calonge y P. J. Quetglas, Madrid / Barcelona, Gredos / Círculo de Lectores, 2007.

Chicharro, D. (ed.), Sta. T. de Jesús, Las moradas del castillo interior, Madrid, Biblioteca Nueva, 1999.

Coenen, E., "Calderón y la guerra: del Sitio de Bredá al sitio de Galera», Nueva Revista de Filología Hispánica, 56.1, 2008, pp. 31-51.

Entwistle, W. J., «La controversia en los autos de Calderón», Nueva Revista de Filología Hispánica, 2.3, 1948, pp. 223-238.

Galván, L., "El lirio y la azucena, auto sacramental de Calderón de la Barca: historia y alegoría», en Miscelánea en el cincuentenario de la creación de la diócesis de Huelva, coord. J. M. ${ }^{a}$ Padilla Valencia, Huelva, Diputación Provincial de Huelva, 2004a, vol. 2, pp. 59-99.

- (ed.), P. Calderón de la Barca, El cubo de la Almudena, Pamplona / Kassel, Universidad de Navarra / Reichenberger, 2004b.

— «Auto sacramental y aventuras caballerescas: La divina Filotea de Calderón», en La dramaturgia de Calderón: técnicas y estructuras (Homenaje a Jesús Sepúlveda), ed. I. Arellano y E. Cancelliere, Madrid / Frankfurt, Iberoamericana / Vervuert, 2006a, pp. 215-228.

- (ed.), P. Calderón de la Barca, La divina Filotea, Pamplona / Kassel, Universidad de Navarra / Reichenberger, $2006 \mathrm{~b}$.

Greer, M. R., «Cazadores divinos, demoníacos y reales en los autos de Calderón de la Barca», en Divinas y humanas letras. Doctrina y poesía en los autos sacramentales de Calderón (Actas del Congreso Internacional, Pamplona, Universidad de Navarra, 26 de febrero-1 de marzo, 1997), ed. I. Arellano, J. M. Escudero, B. Oteiza y M. ${ }^{a}$ C. Pinillos, Kassel, Reichenberger, 1997, pp. 217-244.

Güntert, G., La comedia social de Calderón: discurso social y sabiduría poética, Vigo, Academia del Hispanismo, 2011.

Melo, F. M. de, Historia de los movimientos, separación y guerra de Cataluña, ed. J. Estruch Tobella, Madrid, Castalia, 1996.

Mexía, P., Silva de varia lección, ed. I. Lerner, Madrid, Castalia, 2003.

PArker, G., La revolución militar: las innovaciones militares y el apogeo de Occidente, 1500-1800, trad. A. Piris, Barcelona, Crítica, 1990. [Título original: Military Innovation and the Rise of the West, 1500-1800, Cambridge, Cambridge University Press, 1988.]

- Historia de la guerra, Madrid, Alianza, 2010.

Poppenberg, G., «Religión y política en algunos autos sacramentales de Calderón", en Calderón: protagonista eminente del barroco europeo, ed. K. y Th. Reichenberger, Kassel, Reichenberger, 2000, vol. 1, pp. 87-116.

Regalado, A., Calderón. Los orígenes de la modernidad en la España del Siglo de Oro, Barcelona, Destino, 1995, 2 vols. 
Reichert, F., «Los viajes políticos: embajadas y diplomacia», en Viajes y viajeros en la Europa medieval, coord. F. Novoa Portela y F.Villalba Ruiz, Madrid / Barcelona, CSIC / Lunwerg, 2007, pp. 197-231.

SaAvedra Fajardo, D., Empresas políticas, ed. S. López, Madrid, Cátedra, 1999.

SÁEz, A. J., «Doctrina, historia y política en cuatro autos de Calderón con la guerra de Cataluña al fondo", en Teatro y religión, ed. J. G. Maestro, Theatralia, 14, 2012, en prensa.

SÁEz AвAD, R., Los grandes asedios de la Época Moderna (siglos XVI-XVII), Madrid, Almena, 2010.

Strosetzki, C., «Paz y guerra en Erasmo, Vives y en escritos españoles sobre el arte militar», en La violencia en el mundo hispánico en el Siglo de Oro, ed. J. M. Escudero y V. Roncero, Madrid, Visor Libros, 2010, pp. 319-336.

SuÁrez de Figueroa, C., Plaza universal de todas ciencias y artes, ed. M. Jalón, Valladolid, Junta de Castilla y León, 2006.

Suárez Miramón, A., "El viaje marítimo del mercader en los autos de Calderón», Anuario Calderoniano, 4, 2011, pp. 379-392.

UsunÁriz, J. M. ${ }^{a}$, España y sus tratados internacionales: 1516-1700, Pamplona, Eunsa, 2006.

Visceglia, M. ${ }^{a}$ A. (ed.), Diplomazia e politica della Spagna a Roma: figure di ambasciatori, Roma, Universidad Roma Tre, 2008.

Weller, T., «Poder político y poder simbólico: el ceremonial diplomático y los límites del poder durante el Siglo de Oro español», en Autoridad y poder en el Siglo de Oro, ed. I. Arellano, Ch. Strosetzki y E. Williamson, Madrid / Frankfurt, Iberoamericana / Vervuert, 2009, pp. 213-239. 